Ocean \& Coastal Management

Archimer

March 2015, Volume 105 Pages 1-14

http://dx.doi.org/10.1016/j.ocecoaman.2014.12.010

http://archimer.ifremer.fr/doc/00244/35564/

(C) 2014 Elsevier Ltd. All rights reserved.

\title{
Non-market use and non-use values for preserving ecosystem services over time: A choice experiment application to coral reef ecosystems in New Caledonia
}

Marre Jean-Baptiste ${ }^{1,4,5,{ }^{*}, \text { Brander Luke }}{ }^{2}$, Thebaud Olivier ${ }^{3}$, Boncoeur Jean ${ }^{1}$, Pascoe Sean ${ }^{4}$, Coglan Louisa $^{5}$, Pascal Nicolas ${ }^{6}$

${ }^{1}$ Univ Bretagne Occidentale, UMR AMURE, F-29238 Brest, France.

2 Brander Ltd, Hong Kong, Hong Kong, Peoples R China.

3 IFREMER, UMR AMURE, ZI Pointe Diable, F-29280 Plouzane, France.

${ }^{4}$ CSIRO Wealth Oceans Flagship Marine \& Atmospher R, Brisbane, QId, Australia.

${ }^{5}$ Queensland Univ Technol, Sch Econ \& Finance, Brisbane, QId 4001, Australia.

${ }^{6}$ Ctr Rech Insulaire \& Observ Environm CRIOBE, Lab Excellence CORAIL USR CNRS EPHE 3278, Moorea, Fr Polynesia.

Corresponding author : Jean-Baptiste Marre, email address : jean-baptistem@spc.int

\begin{abstract}
:
Non-use values (i.e. economic values assigned by individuals to ecosystem goods and services unrelated to current or future uses) provide one of the most compelling incentives for the preservation of ecosystems and biodiversity. Assessing the non-use values of non-users is relatively straightforward using stated preference methods, but the standard approaches for estimating non-use values of users (stated decomposition) have substantial shortcomings which undermine the robustness of their results. In this paper, we propose a pragmatic interpretation of non-use values to derive estimates that capture their main dimensions, based on the identification of a willingness to pay for ecosystem protection beyond one's expected life. We empirically test our approach using a choice experiment conducted on coral reef ecosystem protection in two coastal areas in New Caledonia with different institutional, cultural, environmental and socio-economic contexts. We compute individual willingness to pay estimates, and derive individual non-use value estimates using our interpretation. We find that, a minima, estimates of non-use values may comprise between 25 and $40 \%$ of the mean willingness to pay for ecosystem preservation, less than has been found in most studies.
\end{abstract}

\section{Highlights}

- We propose a pragmatic economic interpretation of non-use values based on time decay. We conduct an empirical application using choice experiments in two coral reef areas. We compute implicitly "a minima" individual estimates of non-use values for users. These estimates of non-use values may comprise between 25 and $40 \%$ of mean willingness to pay. 
Keywords : Discrete choice experiment, Ecosystem services valuation, Non-use values, Time decay, Willingness to pay

\section{Abbreviation}

$\begin{array}{ll}\text { ES } & \text { Ecosystem Services } \\ \text { WTP } & \text { Willingness To Pay } \\ \text { WTA } & \text { Willingness To Accept } \\ \text { NUV } & \text { Non-Use Values } \\ \text { DCE } & \text { Discrete Choice Experiment } \\ \text { CVM } & \text { Contingent Valuation Method } \\ \text { MNL } & \text { Multinomial Logit Model } \\ \text { RPL } & \text { Random Parameters Logit model } \\ \text { EC-RPL } & \text { Error Component Random Parameters Logit model } \\ \text { SNA } & \text { Stated Non Attendance } \\ \text { SA } & \text { Stated Attendance }\end{array}$




\section{Introduction}

Persistently high rates of biodiversity loss and continued over-exploitation of ecosystems are expected to precipitate a major global environmental crisis (Millenium Ecosystem Assessment, 2005). In particular, coastal and marine ecosystems suffer intense and increasing degradation (Barbier, 2012). In order to strike a balance between the use of ecosystems and their preservation, a growing body of research has focused on the consequences of ecosystem changes in terms of social welfare. This is the rationale for the economic valuation of Ecosystems Services (ES), which has rapidly developed as a pragmatic approach to support decision-making in the domain of biodiversity conservation (Liu et al., 2010; TEEB, 2008; Boyd and Banzhaf, 2007; Costanza et al., 1997; Pearce and Moran, 1994). Such valuation is designed to account for all the changes in ES which would usually occur outside the market and therefore without economic signals regarding their contributions to social welfare (Adamowitz, 2004).

The costs or benefits of losing or preserving ecosystem services have been broadly classified into use values (direct or indirect), option values and non-use values (e.g. Turner et al., 2003; Bateman et al., 2002). The latter are recognised to be an important component of the total economic value of ecosystems and an important motivation for enhanced conservation. In the case of coastal and marine ecosystems, for example, non-use values have been estimated for offshore marine conservation zone (e.g. McVittie and Moran, 2010), estuaries protection (e.g. Windle and Rolfe, 2005) or coral reef conservation (Laurans et al., 2013; O'Garra, 2009; Schuman, 2011; Spurgeon, 2004).

However, there are still challenges involved in their identification and quantification (Chan et al., 2012; O'Garra, 2009). This is especially the case when valuation is focused on users of the 
ES (Cummings and Harrison, 1995), a user being defined as any individual who directly (through physical or visual contact) or indirectly benefits from an ecosystem of interest, either passively or actively, and therefore hold direct and indirect use values for the ecosystem services considered.

Non-use values have been the subject of a growing economic literature since Krutilla (1967) first discussed the importance of existence and aesthetic values to conservation. Originally, existence value was the main component of non-use values that was considered (Attfield, 1998; Aldred, 1994; Stevens et al., 1991; Loomis, 1988; Krutilla and Fisher, 1985; Brookshire, 1983) and this was commonly presented as the value assigned by an individual to the good"s continued existence, independent from its use(s) or possible use(s). Other dimensions and terminologies have also been considered, including aesthetic value (Chan et al., 2012; MA, 2005; Krutilla, 1967), bequest value which represents the value attached to preserving a good or service for use by future generations, independent of one"s own use (O"Garra, 2009; MA, 2005; Aldred, 1994; Loomis, 1988), altruistic value (Ojea and Loureiro, 2007; MA, 2005; Aldred, 1994), biospheric value (Ojea and Loureiro, 2007) and intangible and cultural values (Chan et al., 2012; Daniel et al., 2012; MA, 2005). Other authors have also referred to passive-use values (e.g. Hanley et al., 1998; Adamowitz et al., 1998; Carson et al., 1992), in an attempt to emphasize the instrumental or utilitarian dimension of those values in economics. Despite this somewhat confusing diversity in terminology, in recent years, non-use values have often been simply defined as encompassing

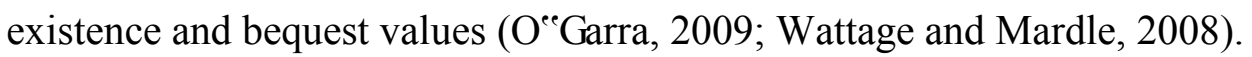

Within the neoclassical economics framework, upon which environmental economics and valuation methods are based, non-use values are defined and measured in monetary units of willingness-to-pay (WTP) or willingness-to-accept (WTA). Non-use values as WTP are 
estimated through stated preference methods, including both the contingent valuation method (CVM) and discrete choice experiments (DCE). Two commonly-used approaches have been used to estimate non-use values. The first is to ask how much respondents are willing-to-pay for an ES (or several of its attributes in case of DCE) which it is absolutely certain they will never use - in this case interviews are based on what we will refer to hereafter as „non-users". The second is to ask respondents, including users, to partition their total WTP for an ES into various categories, such as bequest, existence, own use etc. (e.g. Sattout et al., 2007; Togridou et al., 2006; Walsh et al. 1984). Such stated decomposition approaches have been applied in numerous CVM applications concerning ES and have been helpful in understanding the relative shares of value categories in WTP estimates (e.g. Kontogianni et al., 2012; O'Garra, 2009; Sattout et al., 2007; Kaoru, 1993) or in identifying warm glow effects (Chilton and Hutchinson, 2000). Most of the time, the proportions of non-use values in WTP are found to be quite substantial, representing between 40 and 90\% of total WTP (Kontogianni et al. 2012; Wattage and Mardle, 2008).

Despite its popularity, the stated decomposition approach has substantial shortcomings and is highly controversial, mainly because of the cognitive difficulty of addressing unfamiliar and non-separable components of value (Carson et al., 1999; Cummings and Harrison, 1995; Silberman et al., 1992). An individual's total WTP for an ES is usually a consequence of different overlapping and interrelated motivations, which may be inseparable and as such inaccessible to the researcher (O'Garra, 2009; Cummings and Harrison, 1995; Carson et al., 1992).

As a consequence of these limitations, the first approach (i.e. directly estimating non-use values by deriving non-users ${ }^{\text {ee }}$ WTP/WTA) has been deemed to be more appropriate by some authors 
(e.g. Carson et al., 1992) and is more frequently encountered in the literature (e.g. McVittie and Moran, 2010; Windle and Rolfe, 2005). Although this approach is simpler, since it avoids having to deal with motivations and definitional issues, it constrains the valuation exercise to non-users, which implies a loss of information regarding the non-use values of users. Compared to nonusers, we argue that users may be less subject to a number of biases which have been described in the literature on valuation for non-use values or stated preference methods, such as the "warm-glow" effect described by Kahneman and Knetsch (1992), "yeah-saying" (Blamey et al., 1999), part-whole bias (Hanley et al., 2003), insensitivity to scope and unfamiliarity problems (Barkmann et al., 2008): this is because users have a better knowledge of the ES and a priori defined preferences. They will also tend to feel more concerned about management issues, and this can increase the credibility of the valuation exercise ${ }^{1}$.

There is thus a need to develop and test new frameworks for assessing non-use values that would also allow differentiation and estimation of non-market use and non-use values for users. Besides, there is a need for robust and reliable non-use value estimates regarding marine and coastal ecosystems (Barbier, 2012; McVittie and Moran, 2010; Spurgeon, 2004), especially coral reef and associated ecosystems (Laurans et al., 2013; Schuman, 2011; O'Garra, 2009). In this paper, we propose a methodology to differentiate between use and non-use value components in stated willingness to pay (WTP) estimates, based on time decay. The methodology is tested in an empirical application to the estimation of non-use values associated with preserving New Caledonian coral reef ecosystems.

\footnotetext{
${ }^{1}$ Or make it more complex in case of a polemic issue, with possible strategic behaviors or protests answers.
} 


\section{A pragmatic approach to measuring non-use values}

Economic evaluation of non-use values focuses on the extent to which these values quantitatively affect an individual's or group of individuals ${ }^{\text {ee }}$ economic behavior assumed to be directly observable and measurable in terms of WTP (or WTA). More specifically, we contend that the main characteristic of non-use values for a given ES is the wish (from both users and non-users) that it continue to exist during an indefinite period of time, which will extend beyond the life of the people considered in the evaluation. This does not refer only to existence values, since, for example, it could be mainly motivated by a bequest motivation or be based on other moral grounds (e.g. biocentrism) (Mazzotta and Kline, 1995). We therefore argue that non-use values result in a person ${ }^{\text {es }}$ willingness to preserve the ES in time, from the current moment to beyond the person's own existence. In economic terms, this can be measured via the WTP to preserve the ES over a period of time extending beyond the person's life expectancy. For users, any WTP for preserving the ES during their expected life duration may be linked to both use and non-use values (as well as possibilities for future use i.e. option values). But any WTP for preserving the ES beyond one ${ }^{\text {ee }}$ s expected life-time can be assumed to be an exclusive, although conservative, measure of the non-use values associated with preserving the ES. This can provide an "a minima" estimate, which captures several important dimensions of non-use values, at least the ones commonly considered in the economic valuation literature (bequest and existence values). For non-users, in a temporal dimension, the economic quantification of non-use values can simply be estimated in terms of WTP to preserve any ES over any period of time. Table 1 synthesizes our interpretation in comparison to the commonly encountered estimation procedures of non-use values presented in the introduction. 
Table 1 Estimating Non-use values for users and non-users: a new estimation procedure

\begin{tabular}{|c|c|c|}
\cline { 2 - 4 } \multicolumn{1}{c|}{} & $\begin{array}{c}\text { Commonly encountered estimation } \\
\text { procedures: spatial distance and } \\
\text { stated decomposition }\end{array}$ & $\begin{array}{c}\text { Proposed estimation procedure: } \\
\text { temporal distance and implicit } \\
\text { decomposition }\end{array}$ \\
\hline $\begin{array}{c}\text { Estimation of non- } \\
\text { use values for non- }\end{array}$ & $\begin{array}{c}\text { WTP for preserving ES that are } \\
\text { unreachable or never to be encountered. }\end{array}$ & $\begin{array}{c}\text { WTP for preserving ES over any } \\
\text { time }\end{array}$ \\
\hline $\begin{array}{c}\text { Estimation of non- } \\
\text { use values for users }\end{array}$ & Stated percentage of total WTP for ES \\
currently used & $\begin{array}{c}\text { WTP for preserving ES within life } \\
\text { expectancy: use, option and non-use } \\
\text { values; }\end{array}$ \\
& & $\begin{array}{c}\text { WTP for preserving ES beyond life } \\
\text { expectancy: exclusive non-use } \\
\text { values }\end{array}$ \\
\hline
\end{tabular}

Estimating WTP over several time periods involves using stated preference methods. In order to quantify non-use values, applying the above definition, we propose to use DCE and specify scenarios involving a payment for preserving several ES attributes over time, from the present until a time that lies beyond the individual respondent"s expected lifetime.

\section{Material and methods}

\subsection{Conservation of New Caledonian coral reef ecosystems}

Our empirical application focuses on the conservation of coral reef ecosystems in two coastal areas of New Caledonia (Figure 1). A substantial coral reef complex with more than 4,500 $\mathrm{km}^{2}$ of reef and more than $20,000 \mathrm{~km}^{2}$ of lagoon zones surrounds this territory. New Caledonia has a low-density population of $13.6 / \mathrm{km}^{2}$, with 245,000 inhabitants, of which around two thirds are located in or around the capital city of Nouméa. Interactions between people and the reef vary 
amongst the different cultural groups present in New Caledonia. Part of the population, mostly New Caledonians of European descent and European expatriates, is involved in a service-based economy with a moderate to high purchasing power. Another part, mostly indigenous Kanak people, participates in an economy that relies partly on subsistence agriculture and fishing, and is mainly organized within a tribal system. New Caledonian marine ecosystems are characterised by a high diversity of uses, populations (from a cultural as well as socio-economic perspective), anthropogenic pressures (which can vary from almost none to intense due to important mining industries and urbanization) and associated ecological status. In recognition of its outstanding biodiversity, considered to be of international importance, almost two-thirds of the lagoon area is listed as a UNESCO World Heritage site.

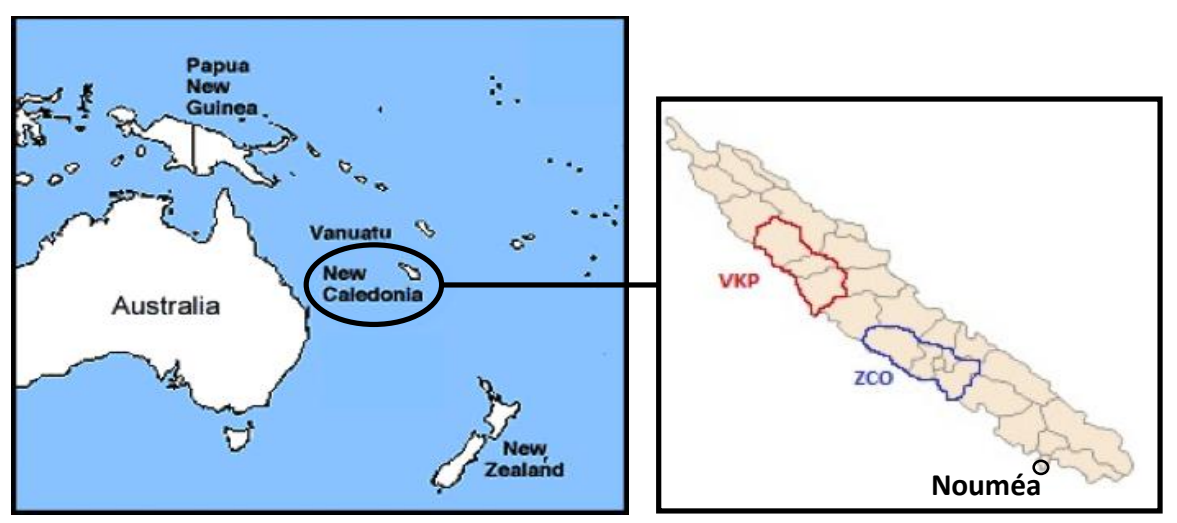

Figure 1 Map of New Caledonia, VKP and ZCO areas

Two sites were selected to represent the different economic, social, institutional and development contexts of the territory (Figure 1). One site, in the Northern Province (Figure 2), is facing pressures from coastal mining, as well as growing development and urbanization, implying important degradation of the vast lagoon and marine ecosystems. These host a high diversity of habitats (coral reefs, sea grasses, mangroves) and species, including several protected ones. The site - called VKP in relation to its three districts: Voh, Koné and Pouembout - has a prevalent indigenous Kanak population. 


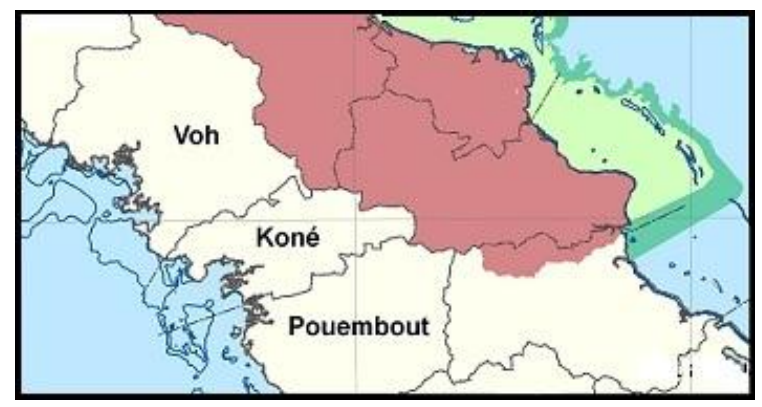

Figure 2 Map of Voh-Koné-Pouembout (VKP) area

The other site (Figure 3) - called "Zone Côtière Ouest" (ZCO) for West Coastal Area - is a UNESCO-listed area covering around $500 \mathrm{~km}^{2}$ of coral reefs, mangroves, sea grass and estuaries, with a further $300 \mathrm{~km}^{2}$ marine and $1700 \mathrm{~km}^{2}$ terrestrial lands buffer zones. It includes five districts in the more populated Southern Province, with a prevalent population of New Caledonians of European descent. The coral reefs and associated ecosystems from this area are globally in good condition. Compared to other areas in New Caledonia, the lagoon is especially narrow in this site, with the reef being close to the shore. That makes it more sensitive to anthropogenic pressures (e.g. erosion, domestic pollution), which are becoming more important as the population of the area is growing with a subsequent increase of marine uses and activities.

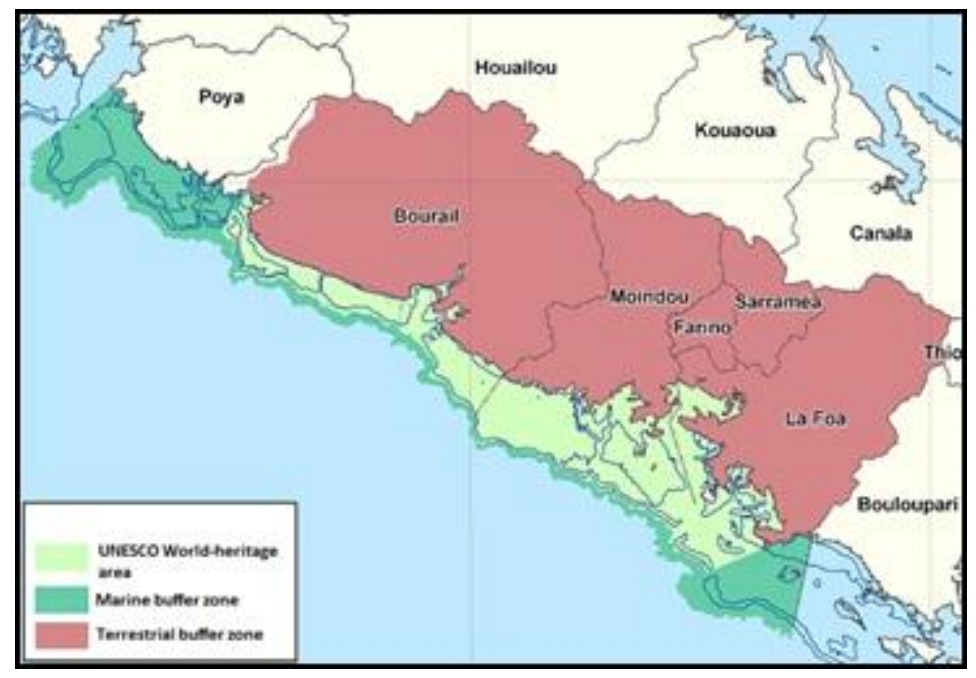

Figure 3 Map of ZCO area and associated UNESCO world heritage zones 
It is important to note that each province in New Caledonia has its own independent political authority with considerable prerogatives, which include managing the economy and the environment.

Individuals in both areas are concerned about future development projects (a considerable mining project in VKP as well as domestic pressures, and a "mega resort" complex in $\mathrm{ZCO}$ ) which imply new conservation issues and a need for management. This was used as the basis for the conservation scenarios presented in the choice experiments. The same survey and choice experiments were conducted in these two areas, in order to study the role of several contextual elements in individuals ${ }^{\text {ee }}$ preferences regarding ecosystem protection over time.

\subsection{Selection of attributes and levels}

The selection of attributes involved several focus group discussions and interviews with different stakeholder groups, followed by tests in the two areas selected. The list of selected attributes and associated levels is presented in Table 2 . Regarding the monetary attribute, a monthly payment in Pacific Francs ${ }^{2}$ (CFP) was finally selected among other possibilities such as willingness-toaccept payment, or willingness to spend time. This kept the exercise simple and generic, the DCE being conducted in two areas with different institutional and socio-cultural contexts. The payment was presented as being per household, but the respondents were asked to answer as the household ${ }^{\text {ee }}$ representatives and according to their own preferences. The other attributes included were:

\footnotetext{
${ }^{2}$ In 2013,100 CFP was equal to around $0.84 €$ or 1.08 US\$.
} 
- The quantity of animals fished, referring to the total catches of finfish, crustaceans, molluscs etc. from the different fisheries (recreational, commercial, subsistence/traditional) in the area, which can be sustained over the long term.

- The health and richness of marine life, referring to ecological conditions of coral reef and associated ecosystems: abundance and diversity of habitats and species, as well as water quality.

- The coastal and lagoon natural landscapes, referring to the natural aspect of current coastal (mangroves, beaches, estuaries, bays) and lagoon (islets, reefs) landscapes.

- The areas of practice, referring to places (coast and lagoon) that people and the community currently use for common activities.

Three time horizons of preservation were chosen after a number field tests: $\mathbf{2 0 , 5 0}$ and $\mathbf{1 0 0}$ years. These levels imply the possibility to preserve the attributes over life expectancy, which is necessary to test our interpretation of non-use values. The status quo was interpreted and presented to respondents as "what would happen in the future if no additional preservation measures were taken". This involved progressive degradation of marine ecosystems due to the rapid undergoing changes in both areas, in view of the different local development projects under way, the growing number of recreational users in the lagoon and external environmental pressures (e.g. climate change).

The alternative scenarios implied a monthly payment that could be used by local organisations to guarantee the preservation of coral reefs and associated ecosystems in each area during 20, 50 or 100 years. Each month, part of the payment could be secured (e.g. in a trust fund) to guarantee 
preservation over longer periods of time (i.e. 50 or 100 years). The payment duration was presented as being for several years with a maximum of 20 years $^{3}$.

Table 2 Attributes and levels

\begin{tabular}{|c|c|c|}
\hline Attributes & Levels & Status quo \\
\hline Payment & $\begin{array}{l}\mathbf{5 0 0}, \mathbf{1 0 0 0}, \mathbf{1 5 0 0}, 2000 \text { cfp per } \\
\text { month }\end{array}$ & $0 \mathrm{cfp}$ \\
\hline Quantity of fished animals & $\begin{array}{l}\text { Preservation for } \mathbf{2 0}, \mathbf{5 0} \text { or } \mathbf{1 0 0} \\
\text { years }\end{array}$ & Progressive decline over time \\
\hline $\begin{array}{c}\text { Health and richness of } \\
\text { marine life }\end{array}$ & $\begin{array}{l}\text { Preservation for } \mathbf{2 0}, \mathbf{5 0} \text { or } \mathbf{1 0 0} \\
\text { years }\end{array}$ & Progressive degradation over time \\
\hline $\begin{array}{c}\text { Coastal and lagoon natural } \\
\text { landscapes }\end{array}$ & $\begin{array}{l}\text { Preservation for } \mathbf{2 0 , 5 0} \text { or } \mathbf{1 0 0} \\
\text { years }\end{array}$ & $\begin{array}{l}\text { Less natural areas and more } \\
\text { constructions }\end{array}$ \\
\hline Areas of practice & Secured for 20,50 or 100 years & $\begin{array}{l}\text { Sufficient areas of practice not } \\
\text { guaranteed for future }\end{array}$ \\
\hline
\end{tabular}

The potential lack of credibility of the choice experiment was carefully considered: for example by reminding respondents of their budget constraint or justifying the relevance of the choices in view of the broad context of global (e.g. climate change) and local (e.g. mining, growing marine activities) pressures, and associated risks for the future. The questionnaire and choice scenarios were also presented as being supported by the French government and the local authorities, to reinforce the legitimacy of the exercise.

\footnotetext{
${ }^{3}$ Such payment duration could imply some heterogeneity regarding the way the payment was taken into account, especially between young and old individuals. Nevertheless, none of the respondents did ask about the payment duration. Besides, our results show that younger individuals are actually willing-topay more than older individuals, and this tends to indicate that they did not feel penalized by the payment vehicle (these results are available upon request).
} 


\subsection{Questionnaire, survey design and data}

In order to create the various choice scenarios to be used in the DCE, a statistical design was first developed to generate random alternatives and organize them in several choice tasks amongst which respondents were then able to choose their most preferred alternative.

The statistical design for the choice experiment was generated using SSI Web 6.0 Sawtooth Software ${ }^{4}$. The number of random alternatives in each choice task was set to two (unlabelled), with a third fixed alternative corresponding to the status quo. A 48 choice task design was generated and blocked into six different versions of eight choice tasks. This final number of choice tasks was selected after field tests, design simulation, and design efficiency comparisons with lower choice tasks. The statistical design was tested using SSI Web 6.0 and found to be efficient using D-efficiency comparisons ${ }^{5}$.

Within the survey itself, an option of "Choice refusal" was added, so that the individuals who refused to participate in the exercise could say so (with a follow up question asking for their reasons). This avoided the assumption that these individuals had a preference for the status quo, while they were in fact opposed to the choice exercise itself, or to the formulation of the management problem.

\footnotetext{
${ }^{4}$ The selected method by which the random choice tasks were generated is complete enumeration (Chrzan et Orme, 2000), allowing us to produce an orthogonal main effects fractional factorial design, which was balanced and with minimal overlap.

${ }^{5}$ A comparison of D-efficiency was conducted with a random design (instead of complete enumeration that we used) - same test specifications (Chrzan et Orme, 2000), and with another design with 30 versions instead of 6 - same test specifications (MNL and simulated response data).
} 
Several field tests and reviews were conducted in order to make sure the questions were clear and understandable. The survey included several sections aimed at collecting extensive information on the socio-economic background of the respondent and their household, on their uses of marine ecosystems (and those by their households), on their perception of preservation issues and on the choices made during the DCE section. The last section regarding choices also included questions about choice heuristics, mainly to examine whether individuals considered all the attributes in selecting an option: this method has been referred to as the stated nonattendance approach (e.g. Hussen Alemu et al., 2012). More precisely this was done by asking individuals to state and rate the way they considered each attribute. The objective behind these questions was to help cope with the main potential limit of our methodology, namely the potential lack of credibility of our scenarios and the associated payment mentioned earlier, by looking at the way individuals considered the payment attribute (or not).

The target population of the survey was all the residents in the areas selected (ZCO and VKP). A random stratified sampling method based on quotas derived from the last population and socioeconomic census data from the "Institut de la Statistique et des Etudes Economiques" (ISEE, 2009 and 2004) was used for sample selection. Several representative quotas for the surveys were thus identified for each area and each district, with the following criteria: age, gender, cultural origin, populations living in tribes; socio-professional categories. The total target number of surveys was set to 250 for the ZCO area, and 300 for the VKP area, leading to a total of 550 surveys. The face-to-face interviews were conducted from November 2011 to February $2012^{6}$

${ }^{6}$ The surveys were conducted through the help of a professional survey company and with local experienced and trained interviewers. All interviews were supervised in order to guarantee reliable data. 


\subsection{Econometric analysis}

The econometric analysis of observed choice response is based on Random Utility Theory (Mc Fadden, 1974; Thurstone, 1927), where an individual's utility function is described as the sum of two different components: a rational one (i.e. corresponding to explainable factors of choice, such as the attributes and their associated levels), and a random one (i.e. unexplainable factors of choice). In the modeling framework, it is then assumed that an individual chooses the alternative that maximizes his utility, which is studied in terms of probability. Based on the assumptions made regarding both the rational and random components of utility, various choice models can be used to represent choice probabilities.

All our econometric analysis was conducted using NLogit 4.0. In the first stage of the analysis, a simple modeling approach based on Multinomial Logit (MNL) models (Mc Fadden, 1974) was used to examine the data and specify the utility functions, defined as a sum of the monetary attribute with its associated parameter, the different attributes levels with their associated parameters, an alternative specific constant associated with the status quo and a Gumbeldistributed error term.

However, the MNL model implies strong assumptions (Train, 2003), and may not reflect the complexity of the choice process (Hensher et al., 2005). Further models were thus tested in the second stage of the analysis, including the Error Component Logit model, the Random Parameters Logit model (RPL) (Train, 2003) and the Latent Class Model (Swait, 1994). A modeling approach combining both Error Component and Random Parameters Logit model (EC-RPL) was finally selected for several reasons: (1) it is the one providing some of the highest model fits as well as the best predictions amongst the models tested; (2) it allows coping with preference heterogeneity at the individual level, which is crucial in view of the different 
populations and areas targeted by our survey; (3) it offers the possibility to deal with potential attribute non-attendance issues using stated attendance data (Hess and Hensher, 2010).

The RPL assumes that preference intensities vary continuously across respondents. When using an RPL, the analyst has to specify the distribution of the attribute coefficients. Normal distributions are the most commonly encountered within the literature (Hensher et al., 2005), and we initially tested such distributions for our non-monetary attributes. However, when the sign of the coefficient is not expected to change and stays either positive or negative, constrained distributions can be used, such as the constrained triangular distribution. If heterogeneity is observed for the cost parameters, it is usually recommended that the constrained triangular distribution be used ${ }^{7}$ (e.g. Scarpa et al., 2013; Beharry-Borg and Scarpa, 2010); and this is the one we used.

Due to our design involving repeated choices with a fixed alternative (status quo), an error component specification was also used. This type of model has been shown in the literature to produce higher model fit and robustness in this context (Hess and Rose, 2009), by incorporating a zero-mean normally distributed random parameter (i.e. the error component, usually noted $\mu$ ) additional to the usual Gumbel-distributed error term in the non-status quo alternatives. The error component aims at capturing any status quo effects in the stochastic part of the utility, i.e. any additional variance associated with the process of choosing experimentally designed alternatives over the status quo (Scarpa et al., 2005; Train, 2003).

\footnotetext{
${ }^{7}$ This leads to more behaviorally plausible WTP estimates, and also insures a negative cost parameter (Hensher and Greene, 2003).
} 
In the end the utility function takes the form below, with three alternatives $\mathrm{i}=1,2,3$ (the third being the status quo), for individual $\mathrm{n}$, and choice set $\mathrm{s}$. In this utility function, $\beta_{\mathrm{k}}$ are randomly distributed.

$$
U_{\text {sin }}=\left\{\begin{array}{l}
V_{\text {sin }}\left(\beta_{k}, X_{k}, \mu\right)+\varepsilon_{\text {sin }}, i=1,2 \\
V_{\text {sns }}\left(A S C s q, \beta_{k}, X_{k}, \mu\right)+\varepsilon_{\text {sin }}, j=3 \text { (status quo) }
\end{array}\right.
$$

In deriving WTP, once the parameters have been estimated, the analyst must take into account the fact that some parameters are randomly distributed. Both unconditional and individualspecific WTP estimates can be estimated (Hensher et al., 2005). Estimating WTP at the individual level (rather than averaging WTP on all the population) produces more accurate estimates since this takes into account taste heterogeneity at the individual level (Green et al., 2005; Hensher et al., 2005). Based on Bayes"e theorem, the simulation-based estimator for the individual WTP is defined by the ratio of the non-monetary attribute"es distribution and the cost attribute distribution weighted by the likelihood function (Green et al., 2005), and the produced estimates are thus conditional on the observed individual choices $\mathrm{y}_{\mathrm{n}}$ and attribute values $\mathrm{x}_{\mathrm{n}}$ (Train, 2003).

This conditional parameters estimation procedure was used in order to estimate non-use values at the individual level, in accordance with our definition of such values.

\section{Results}

Of the 550 individuals surveyed, 116 were discarded as they either did not complete all the choice tasks, completed the tasks but stated that they did it randomly (no understanding of the exercise), or stated that they refused to make choices for various reasons that cannot be considered as a preference for the status quo (e.g. they did not understand the CE, they were 
firmly opposed to such a payment scenario, they thought the choices were not relevant or not realistic). Almost all our respondents were users of the reef, and the few non-users were among the discarded individuals. Socio-economic characteristics of individuals retained for our analysis are presented in table 3, for each area.

Table 3 Socio-economic characteristics of individuals retained for analysis, for each area

\begin{tabular}{|c|c|c|}
\hline & VKP & $\mathrm{ZCO}$ \\
\hline Age (average) & 40 & 43 \\
\hline Gender (average) & $49 \%$ male & $51 \%$ male \\
\hline Monthly net income per household (average) & 260,000 to $310,000 \mathrm{cfp}$ & $\begin{array}{l}170,000 \text { to } 260,000 \\
\operatorname{cfp}\end{array}$ \\
\hline Level of Education (average score out of $5^{\mathrm{i}}$ ) & 2 & 1.7 \\
\hline Living in Tribe (average) & $50 \%$ & $22 \%$ \\
\hline
\end{tabular}

In addition, around half of the individuals who completed the eight choices declared having not paid serious attention to the payment attribute and its associated levels, implying that no WTP can be derived for these individuals if their statements are correct (Scarpa et al., 2009). Two subgroups were therefore identified and differentiated during the second stage of the analysis where panel EC-RPL models were used to estimate individual WTP: one sub-group having stated attendance to payment (SA group), the other one having stated non-attendance (SNA group).

\subsection{Utility specification}

Here, we present the results from three MNL models (one for each area and one for both areas together), and two EC-RPL models (one for each area) (table 4). 
Table 4 MNL and Panel EC-RPL model results for each area with non monetary attributes under non continuous form

\begin{tabular}{|c|c|c|c|c|c|c|c|c|}
\hline & \multicolumn{3}{|c|}{ MNL } & \multicolumn{4}{|c|}{ EC-RPL } & \multirow{3}{*}{ Distribution } \\
\hline & \multirow{2}{*}{$\begin{array}{c}\begin{array}{c}\text { Pooled } \\
\text { (coeff. } \\
\text { normalized) }\end{array} \\
\end{array}$} & \multirow{2}{*}{$\begin{array}{c}\text { VKP } \\
\text { (coeff. } \\
\text { normalized) }\end{array}$} & \multirow{2}{*}{$\begin{array}{c}\text { ZCO } \\
\text { (coeff. } \\
\text { normalized) }\end{array}$} & \multicolumn{2}{|c|}{ VKP } & \multicolumn{2}{|c|}{ ZCO } & \\
\hline & & & & Mean & $S . D$ & Mean & $S . D$ & \\
\hline Payment & $-0,00015^{* * *}$ & $-0.00020^{* * *}$ & $-0.00010^{*}$ & $-0.00044 * * *$ & $0.00044 * * *$ & $-0.00025 * * *$ & $0.00025 * * *$ & $t, 1$ \\
\hline Catches 20 years & $0,615^{* *}$ & $0,638^{*}$ & 0,613 & $0.166^{* *}$ & $0.392 * * *$ & $0.187^{*}$ & $0.652 * * *$ & $\mathbf{n}$ \\
\hline Catches 50 years & $0,736^{* * *}$ & $0,776^{* * *}$ & $0,709^{* * *}$ & $0.350^{* * *}$ & $0.392 * * *$ & $0.366^{* * *}$ & $0.652 * * *$ & $\mathbf{n}$ \\
\hline Catches 100 years & $0,756 * * *$ & $0,780^{* * *}$ & $0,826 * * *$ & $0.340^{* * *}$ & $0.392 * * *$ & $0.629^{* * *}$ & $0.652 * * *$ & $\mathbf{n}$ \\
\hline Health 20 years & $0,899^{* * *}$ & $0,972 *$ & $0,828^{* *}$ & $0.216^{*}$ & $0.655 * * *$ & $0.319^{* *}$ & $0.849 * * *$ & $\mathbf{n}$ \\
\hline Health 50 years & $1,053 * * *$ & $1,215^{* * *}$ & $0,893 * * *$ & $0.550 * * *$ & $0.655^{* * *}$ & $0.404 * * *$ & $0.849 * * *$ & $\mathbf{n}$ \\
\hline Health 100 years & $1,131^{* * *}$ & $1,274 * * *$ & $0,993 * * *$ & $0.677 * * *$ & $0.655 * * *$ & $0.758 * * *$ & $0.849 * * *$ & $\mathbf{n}$ \\
\hline Landscape 20 years & $0,663 * * *$ & $0,632 * * *$ & $0,706^{*}$ & $0.203^{* *}$ & $0.444 * * *$ & $0.225^{* *}$ & $0.549 * * *$ & $\mathbf{n}$ \\
\hline Landscape 50 years & $0,674 * * *$ & $0,647 * * *$ & $0,720^{* *}$ & $0.304 * * *$ & $0.444 * * *$ & 0.177 & $0.549 * * *$ & $\mathbf{n}$ \\
\hline Landscape 100 years & $0,792 * * *$ & $0,645^{* * *}$ & $0,984 * * *$ & $0.321 * * *$ & $0.444 * * *$ & $0.865 * * *$ & $0.549 * * *$ & $\mathbf{n}$ \\
\hline Areas 20 years & 0,311 & 0,342 & $0,283^{* *}$ & 0.058 & 0.183 & $-0.325^{* * *}$ & $0.610^{* * * *}$ & $\mathbf{n}$ \\
\hline Areas 50 years & $0,647 * * *$ & $0,634 * * *$ & $0,674 * * *$ & $0.540^{* * *}$ & $0.570 * * *$ & $0.505^{* * *}$ & 0.094 & $\mathbf{n}$ \\
\hline Areas 100 years & $0,451 * *$ & 0,226 & $0,707 * * *$ & -0.0820 & 0.254 & $0.715^{* * *}$ & $0.785 * * *$ & $\mathbf{n}$ \\
\hline ASCsq & $0,299 * * *$ & 0.036 & $0.602 * * *$ & \multicolumn{2}{|c|}{$-5.620 * * *$} & \multicolumn{2}{|c|}{$-7.133^{* * *}$} & \\
\hline Sigma Option 1,2 & & & & \multicolumn{2}{|c|}{0.431} & \multicolumn{2}{|c|}{$5.937 * * *$} & \\
\hline Sigma Status Quo & & & & \multicolumn{2}{|c|}{$6.023 * * *$} & \multicolumn{2}{|c|}{$5.560 * * *$} & \\
\hline Final Log-Likelihood & & -1509.6 & -1419.3 & \multicolumn{2}{|c|}{-1213.1} & \multicolumn{2}{|c|}{-1138.8} & \\
\hline $\mathrm{AIC}$ & & 1.561 & 1.682 & \multicolumn{2}{|c|}{1.265} & \multicolumn{2}{|c|}{1.362} & \\
\hline Adjusted Pseudo-R ${ }^{2}$ & 0,108 & 0,111 & 0,115 & \multicolumn{2}{|c|}{0.431} & \multicolumn{2}{|c|}{0.388} & \\
\hline Halton Draws & & & & \multicolumn{2}{|c|}{350} & \multicolumn{2}{|c|}{350} & \\
\hline $\mathrm{N}$ & 457 & 244 & 213 & \multicolumn{2}{|c|}{244} & \multicolumn{2}{|c|}{213} & \\
\hline
\end{tabular}

*** Significant at the $1 \%$ level** Significant at the $5 \%$ level * Significant at the $10 \%$ level 
278 We focus on two main results: first an original specification of the utility function where some

279 attributes enter the utility under a non-linear continuous form (namely logarithmic); second, the

280 differences between both areas. The influence on these results of several socio-economic

281 variables entering the utility function (age, income, gender, life in tribe, and level of education)

282 is further examined in appendix A.

283 While almost all model parameters are significant in the MNL models, the fit is poor (adjusted 284 pseudo- $\mathrm{R}^{2}=0.108$ ), suggesting that not all of the important information is being captured. This is 285 probably linked to the simplicity of the MNL and the assumption of independent choices and 286 preference homogeneity.

287 The "price" parameter (only significant at the 10\% level for the ZCO area) was also found to be 288 very low, resulting in the WTP estimates being unrealistically high and far higher than the actual 289 maximum payment proposed within the experiment (2000 FCFP/month) for both the pooled 290 model and the area specific models. The MNL models presented in appendix A show significant 291 effects for the socio-economic variables, which differ between the two areas. In the pooled 292 model, younger individuals are more willing to choose alternatives with preservation over time, 293 as well as individuals with higher income, higher education level and individuals living in tribe.

294 The poor model fits and predictions encountered with the MNL models imply a need for further 295 analysis in two directions: relaxing the MNL assumption regarding preference homogeneity and 296 including the panel nature of our data (i.e. one individual made eight choices), both of which are 297 addressed with the panel EC-RPL models.

298 The model fits are substantially higher in the panel EC-RPL models (table 4). Again, almost all 299 parameters are significant and with significant associated standard deviations, implying 300 important preference heterogeneities within the populations of each area. A constrained 
301 triangular distribution where the standard deviation equals the mean was used for the payment 302 parameters in order to take into account the potentially important level of heterogeneity 303 associated with consideration of the payment during the choices. Estimated WTP with these 304 models were also found to be unrealistically high. This could probably be explained by the fact 305 that some individuals may not have considered the payment during their choices (which would 306 confirm the attendance statements in the follow-up questions), i.e. that there is a strong cost307 attribute non-attendance. Almost none of the socio-economic variables are significant in the EC308 RPL (Appendix A), the socio-economic effects being captured by the random parameters.

309 An interesting result from these first models is that the first three non-monetary attributes 310 (Quantity of animals fished, Health and richness of the marine life, Coastal and lagoon natural 311 landscapes) could all be considered as continuous, but in a non-linear way. A graphic 312 representation of the different part-worth utilities of those three first attributes is shown in Figure 3134 , extrapolated from our four points through time in the pooled MNL.

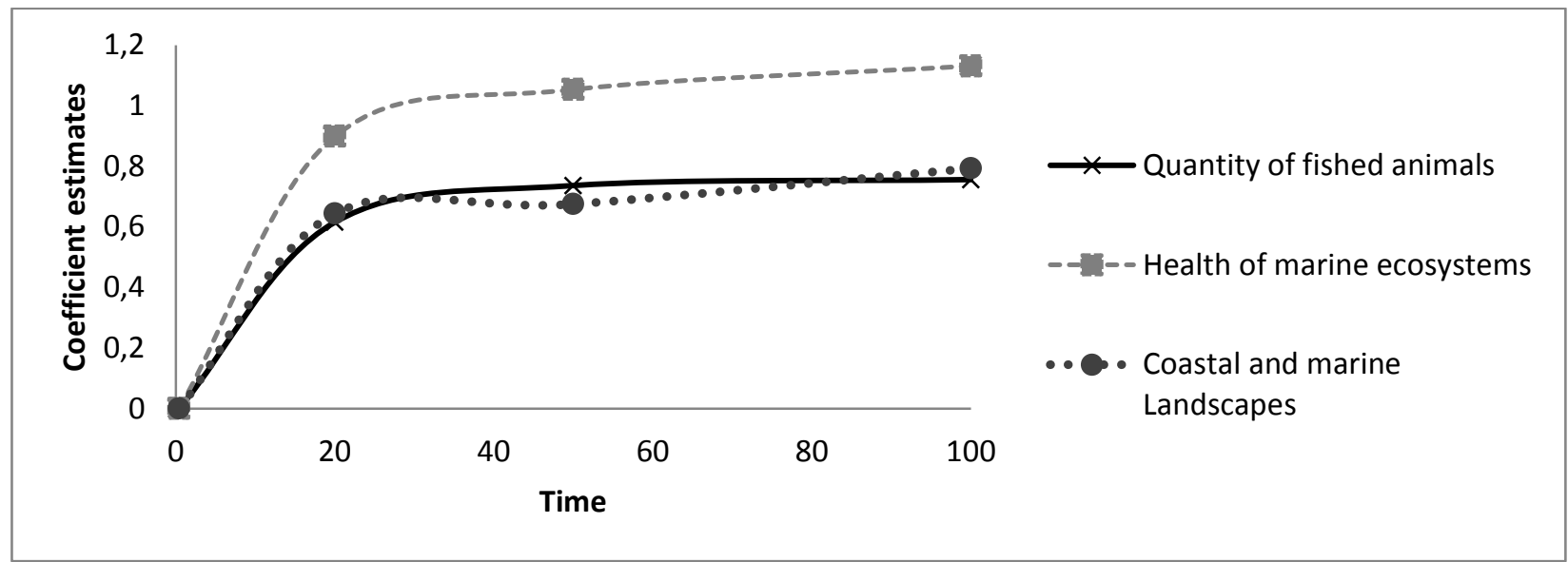

Figure 4 Non-linear utility of preservation over time of the Quantity of animals fished, the Health and richness of the marine life, the Coastal and lagoon natural landscape 
314 In this figure, the base level of the attributes (status quo) is set as 0 in terms of part worth 315 utilities (dummy coding), and corresponds to a protection period of around 4 months. The three 316 curves clearly have a logarithmic shape.

317 Based on this initial set of results, we considered that the three attributes could enter the utility 318 function as a logarithm function, with a value defined as -1 for the status quo level 319 (corresponding to preservation for around 4 months). There are however significant differences 320 between the two areas, in particular regarding the attribute "areas of practice". For the ZCO, this 321 attribute displays similar logarithmic shaped part-worth utilities. For VKP, however, only the 50 322 years preservation level is significant. This result can be interpreted in relation to the contexts of 323 these areas: in $\mathrm{ZCO}$, the lagoon is very narrow, with significant parts being marine reserves, thus 324 implying conflicts of uses and concerns from the populations regarding their potential areas of 325 practices, thus strong attention is paid to this attribute during the choices. In VKP, however, 326 there are no reserves and the lagoon is large, with limited conflicts regarding areas of practice, 327 thus explaining the lower attention paid to this attribute.

328 To take this into account in the analysis, the last non-monetary attribute (areas of practice) was 329 kept under its previous non-continuous form for VKP, and entered as a logarithm function for 330 ZCO. This new utility specification with logarithmic functions was then tested using MNL and 331 panel EC-RPL models for each area (table 5). Again, almost all the parameters were highly 332 significant, and the WTP estimates appeared unrealistic, given very low payment parameter 333 values (see tables 5 and 6 for estimated WTP with the log-linear specification). As mentioned 334 above, this is likely due to a potentially strong cost-attribute non-attendance, which requires 335 adapting our estimation procedure (see next section). 
Table 5 MNL and Panel EC-RPL for each area with log-linear utility specification (WTP are in cfp/month)

\begin{tabular}{|c|c|c|c|c|c|c|c|c|c|}
\hline & \multicolumn{4}{|c|}{ MNL } & \multicolumn{4}{|c|}{ EC-RPL } & \multirow{3}{*}{ Distribution } \\
\hline & \multicolumn{2}{|l|}{ VKP } & \multicolumn{2}{|c|}{$\mathrm{ZCO}$} & \multicolumn{2}{|c|}{ VKP } & \multicolumn{2}{|c|}{$\mathrm{ZCO}$} & \\
\hline & Coeff. & WTP & Coeff. & WTP & Mean & S.D. & Mean & S.D. & \\
\hline Payment & $-0.00024 * * *$ & & $-0.00010^{*}$ & & $0.00037^{* * *}$ & $0.00037^{* * *}$ & $0.00015^{* * *}$ & $0.00015^{* * *}$ & $\mathrm{t}, 1$ \\
\hline Ln Catches & $0.146^{* * *}$ & 616 & $0.135 * * *$ & 1290 & $0.168^{* * *}$ & $0.168^{* * *}$ & $0.153^{* * *}$ & $0.153 * * *$ & $\mathrm{t}, 1$ \\
\hline Ln Health & $0.229 * * *$ & 965 & $0.180^{* * *}$ & 1723 & $0.299 * * *$ & $0.299 * * *$ & $0.232 * * *$ & $0.232 * * *$ & $\mathrm{t}, 1$ \\
\hline Ln Landscapes & $0.124 * * *$ & 521 & $0.163^{* * *}$ & 1558 & $0.158 * * *$ & $0.158 * * *$ & $0.193^{* * *}$ & $0.193 * * *$ & $\mathrm{t}, 1$ \\
\hline Ln Areas (ZCO only) & & & $0.129 * * *$ & 1233 & & & $0.150^{* * *}$ & $0.150^{* * *}$ & $\mathrm{t}, 1$ \\
\hline Areas 20 years (VKP only) & 0.0545 & & & & 0.047 & & & & fixed \\
\hline Areas 50 years (VKP only) & $0.337 * * * 1$ & 2808 & & & $0.416^{* * *}$ & $0.416^{* * *}$ & & & $\mathrm{t}, 1$ \\
\hline Areas 100 years (VKP only) & -0.059 & & & & -0.063 & & & & fixed \\
\hline ASCsq & -0.0376 & & $0.57^{* * *}$ & & -7.83 & $7 * * *$ & -6.529 & $* * *$ & \\
\hline Sigma Option 1,2 & & & & & 2.5 & & 7.077 & $* * *$ & \\
\hline Sigma Status Quo & & & & & 7.00 & $6 * * *$ & 3.516 & & \\
\hline Final Log-Likelihood & -1514.8 & & -1426.1 & & -12 & 0.5 & -116 & & \\
\hline AIC & 1.560 & & 1.681 & & 1.2 & & 1.37 & & \\
\hline Adjusted Pseudo-R ${ }^{2}$ & 0,112 & & 0,107 & & 0.4 & & 0.37 & & \\
\hline Halton Draws & & & & & 3. & & 35( & & \\
\hline $\mathrm{N}$ & 244 & & 213 & & 2 & & 213 & & \\
\hline
\end{tabular}

*** Significant at the $1 \%$ level** Significant at the $5 \%$ level * Significant at the $10 \%$ level

${ }^{I}$ Effect coded 
Table 6 Panel EC-RPL with log-linear utility specification: individual WTP estimates (cfp/month) and standard deviation estimates of individual WTP for all individuals, in each area

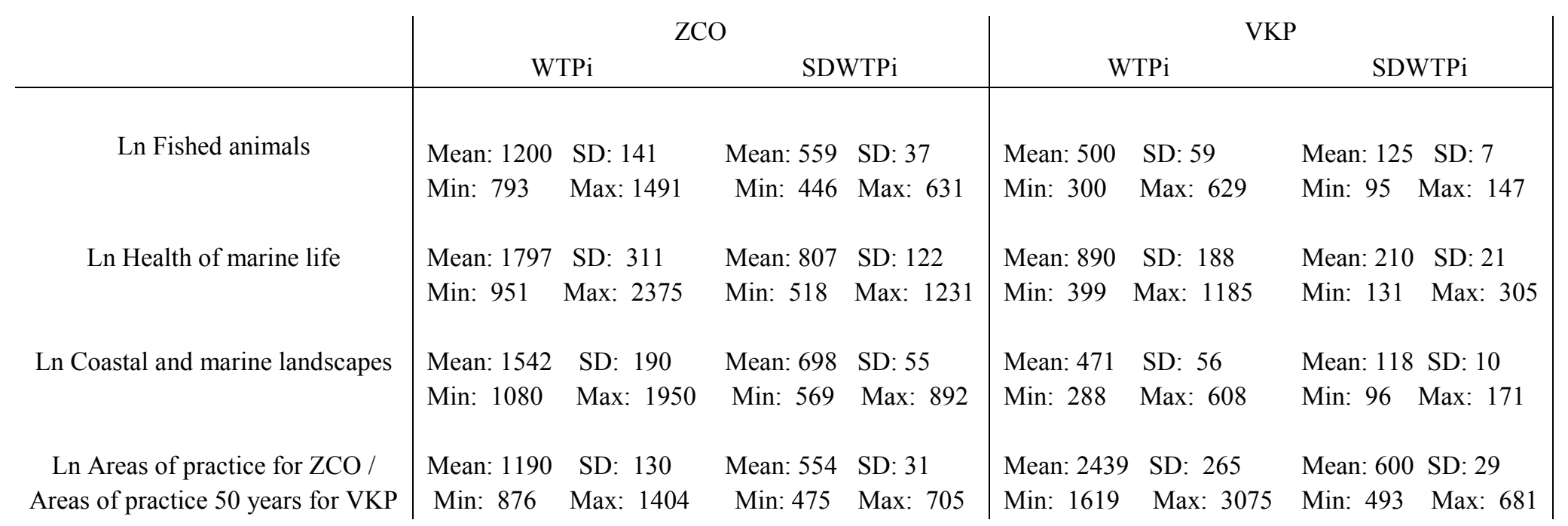


Table 7 Panel EC-RPL with different payment coefficients for individuals who stated attendance or not to payment

\begin{tabular}{|c|c|c|c|c|c|}
\hline & \multicolumn{4}{|c|}{ EC-RPL } & \multirow{3}{*}{ Distribution } \\
\hline & \multicolumn{2}{|c|}{ VKP } & \multicolumn{2}{|c|}{$\mathrm{ZCO}$} & \\
\hline & Mean & S.D & Mean & S.D & \\
\hline Payment SNA group & -0.000092 & & -0.0000045 & & fixed \\
\hline Payment SA group & $-0.00064 * * *$ & $0.00032 * * *$ & $-0.00037 * * *$ & $0.00019^{* * *}$ & $\mathrm{t}, 0.5$ \\
\hline Ln Catches & $0.165^{* * *}$ & $0.165 * * *$ & $0.151 * * *$ & $0.151 * * *$ & $\mathrm{t}, 1$ \\
\hline Ln Health & $0.296 * * *$ & $0.296^{* * * *}$ & $0.231 * * *$ & $0.231 * * *$ & $\mathrm{t}, 1$ \\
\hline Ln Landscaoes & $0.154 * * *$ & $0.154 * * *$ & $0.198 * * *$ & $0.198 * * *$ & $\mathrm{t}, 1$ \\
\hline Ln Areas & & & $0.151 * * *$ & $0.151 * * *$ & $\mathrm{t}, 1$ \\
\hline Areas 20 years & 0.059 & & & & fixed \\
\hline Areas 50 years & $0.399 * * *$ & $0.399 * * *$ & & & $\mathrm{t}, 1$ \\
\hline Areas 100 years & -0.064 & & & & fixed \\
\hline ASCsq & -8.03 & $* * *$ & -6.50 & $5 * * *$ & \\
\hline Sigma Option 1,2 & 0.5 & & 4.73 & & \\
\hline Sigma Status Quo & 7.143 & & 6.030 & *** & \\
\hline Final Log-Likelihood & -122 & & -115 & & \\
\hline AIC & 1.2 & & 1.3 & & \\
\hline Adjusted Pseudo-R ${ }^{2}$ & 0.4 & & 0.3 & & \\
\hline Halton Draws & 35 & & 35 & & \\
\hline $\mathrm{N}$ & 24 & & 21 & & \\
\hline
\end{tabular}

*** Significant at the $1 \%$ level** Significant at the $5 \%$ level * Significant at the $10 \%$ level 
335 The model fits and predictions were similar for both kinds of models, suggesting that the log336 linear specification of the utility functions works as well as the linear non-continuous version.

337 Using this specification enables us to estimate WTP for each additional year of preservation for 338 the continuous non-monetary attributes.

\subsection{Panel EC-RPL with stated cost attendance groups}

339 In order to arrive at more credible WTP estimates, we sought to isolate a group of respondents 340 that did consider the payment during their choices using the non-attendance statements. Two 341 groups were identified: one group who stated none or really low consideration of the payment 342 (SNA group), and another group who stated medium to very strong consideration of the payment 343 (SA group). The SA group represents 82 individuals in the ZCO area (of 213 surveyed), and 113 344 individuals for the VKP area (of 244 surveyed).

345 We then affected each group a separate parameter for the payment following the method recently 346 detailed in Scarpa et al. (2013) and initially proposed by Hess and Hensher (2010), and ran the

347 MNL and panel EC-RPL models again for each areas. Results are presented in table 7. The 348 model fits are significantly higher than the previous models. Both payment coefficients (SNA 349 and SA) were first considered as following a constrained triangular distribution, but only the 350 payment ${ }^{\text {ee }}$ coefficient for the SA group was kept under a random form since both the payment"s 351 coefficient and its associated standard deviation for the SNA group were not significant for each 352 area. The payment parameter for the SA group was strongly significant in each area, confirming 353 the stated cost attribute attendance or non-attendance.

354 All the other parameters for this final model were still strongly significant (except for Areas 20 355 and 100 years in the case of VKP area, as before). The differences observed between the two 
356 areas can be interpreted as reflecting their different socio-economic and ecological contexts. In

357 VKP, an existing mining project will have impacts on the coastal landscapes even with 358 conservation, whereas in ZCO the coastal and marine landscapes have some very distinctive 359 features that are clearly linked to its world heritage label and that inhabitants clearly wish to 360 preserve. Furthermore, the particularly strong preference for the preservation of the health and 361 richness of marine life in the VKP area is also certainly linked to the mining project, which 362 represents a considerable and immediate threat to coastal and marine ecosystems. Finally 363 recreational and indigenous fishing practices are more present in VKP compared to ZCO.

\subsection{Individual WTP and non-use values}

364 Using the above model results, we derived WTP estimates for all the different attributes, 365 considering only the payment coefficient for the SA group, for each area and with the non-linear 366 utility specifications previously selected. For the attributes which enter the utility function under 367 a logarithm form, the associated WTP corresponds to the logarithm of one year of preservation.

368 Based on this, an estimate of WTP for any duration period between 20 and 100 years for the 369 preservation of each of these attributes can be computed. Indeed, the expressions for WTP are 370 obtained by equating $\mathrm{U}\left(\Delta \mathrm{X}_{\mathrm{k}}\right)=\mathrm{U}_{\mathrm{n}}(\Delta$ Payment), leading to the following expressions:

$\beta_{\mathrm{k}} * \log \left(\Delta \mathrm{X}_{\mathrm{k}}\right)=\beta_{\text {price }} * \Delta$ Payment $\Leftrightarrow \Delta$ Payment $=\left(\beta_{\mathrm{k}} / \beta_{\text {price }}\right) * \log \left(\Delta \mathrm{X}_{\mathrm{k}}\right)$

372 As mentioned before, our model allows us to derive WTP at the individual level. Results are

373 reported in table 8 , where the mean, the standard deviation, as well as the minimum and the 374 maximum of estimated individual WTP (and of the estimated Standard Deviation of individual 375 WTP) are presented. The resulting estimates are much lower than the previous estimates (as can 376 be seen from comparing the results presented in tables 6 and 8 ). 
Table 8 Panel EC-RPL with log-linear utility specification: Individual WTP (cfp/month) and standard deviation of individual WTP for individuals who stated attendance to payment, for each area

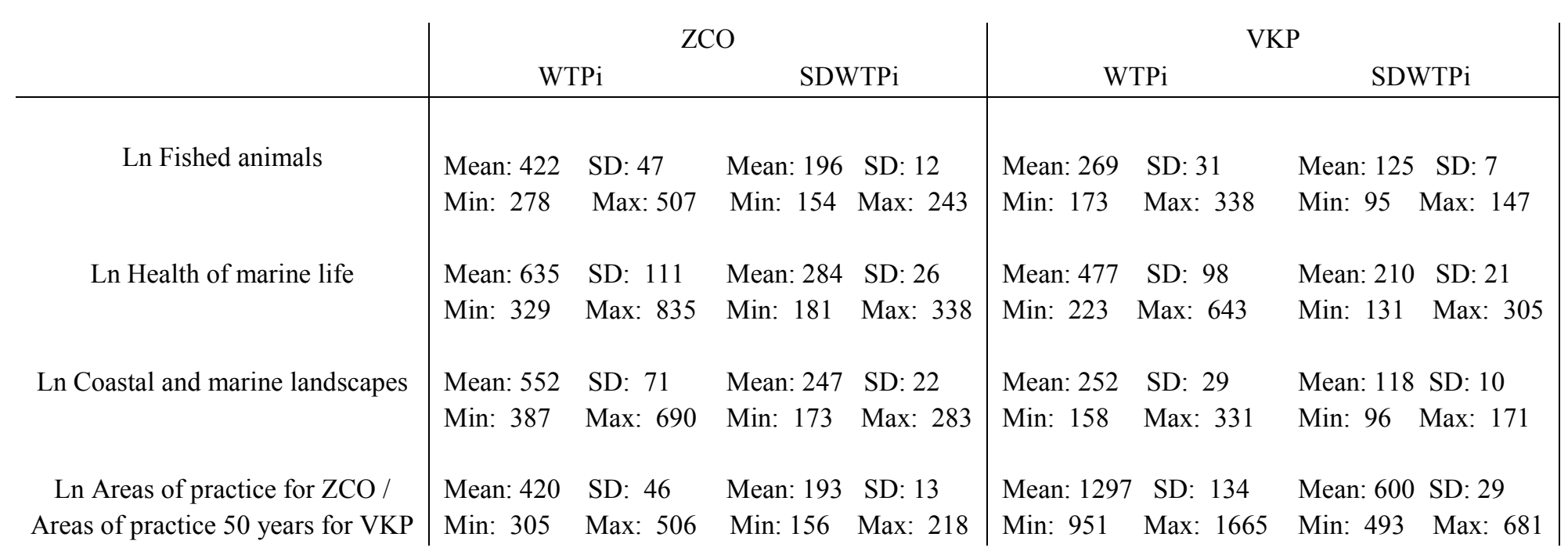



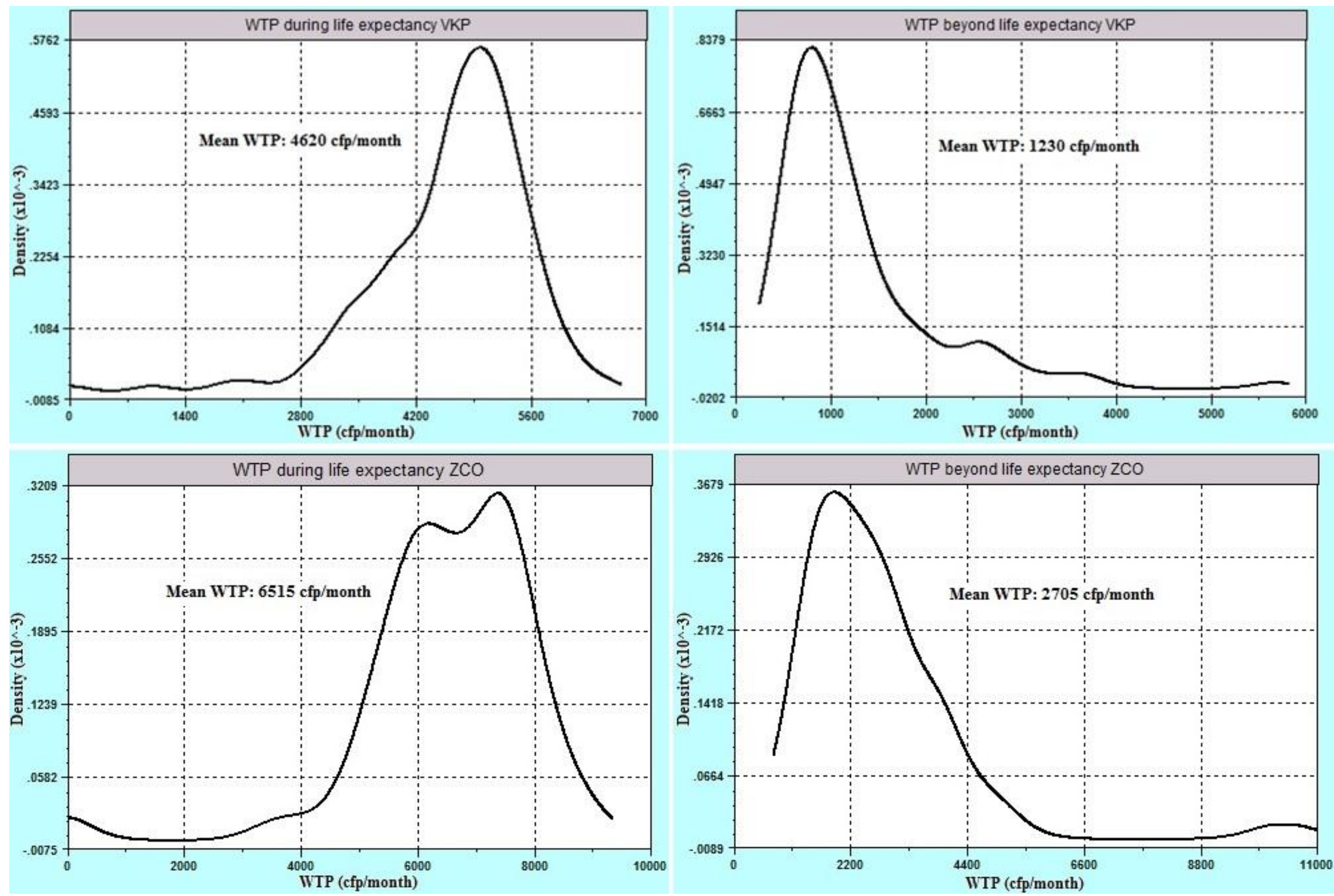

Figure 5 Distribution of individual use and non-use values for VKP and ZCO. Kernel density plots on the left represent individual WTP during life expectancy (use, option and non-use values); the ones on the right represent individual WTP beyond life expectancy (non-use values) 
Using these estimates, we then computed, for each individual, a WTP during and strictly beyond life expectancy, taking into account the individuales current age, in order to assess individual non-use values as per our definition.

Average life expectancy at birth in New Caledonia is 76 years so for each individual we calculated WTP for preservation strictly beyond their expected remaining years of life (76 Individuales age) and until 100 years, as a measure of the non-use value component, and WTP for preservation during their expected remaining years of life, measuring a combination of use and non-use values as well as option values. To be consistent with our definition, for the very few respondents who were actually older than 76 years, we considered their WTP for any additional year of preservation as non-use values. The validity of this assumption is reinforced by the fact that these individuals stated in the questionnaire very little interaction with the coastal and marine ecosystems, due to their age and location. For both areas WTP during and after life expectancy were thus calculated for each non-monetary attribute. However, for the VKP area, since the attribute area of practice could not be considered under a continuous form, non-use values were estimated only for people over 76 years old (through the WTP for 50 years of preservation), which explains why their part in total WTP is smaller compared to ZCO area. Similarly, the WTP for 50 years of preservation of the areas of practice in VKP were considered as entering WTP during life expectancy for individuals below 76 years old. Total individual WTP were then derived by adding up WTP estimates for the different attributes.

The Kernel density estimator plots for individual WTP estimates (Hensher et al., 2005), both during and beyond life expectancy for each area, are shown in Figure 5. The mean of individual specific WTP are shown on each graph. The calculated non-use value component of total WTP for preserving all the attributes over 100 years at the level of our sample represents at least $27 \%$ of total WTP for VKP and $41 \%$ for ZCO. This estimated "a minima" NUV component of WTP 
depends exclusively on the age of the individuals, since there is a maximum preservation time (100 years). It is therefore important to also consider the minimum and maximum estimated non-use values, which are respectively around 1,000 and $10,500^{8} \mathrm{cfp} / \mathrm{month}$ for ZCO; and around 400 and $5,700 \mathrm{cfp} / \mathrm{month}$ for VKP. As such, they range from $11 \%$ to $100 \%$ of individuals total WTP for preservation of the different attributes over 100 years.

\section{Discussion and conclusions}

Several important results from our case study can be pointed out.

Regarding our main objective, which was to examine a pragmatic approach to measuring nonuse values, several key results can be highlighted. First, our approach allowed us to specify partworth utilities regarding the preservation of the different attributes over time under a logarithmic form. This is in itself a significant contribution to the DCE literature, where it has been argued that linear utility function specifications are not likely to be robust due to the existence of diminishing marginal utilities or gain-loss asymmetries, which is an important limit of current practice in DCE (Hoyos, 2010). This also confirms the theoretical basis of our approach. Second, we were able to implicitly isolate a minima, but exclusive, non-use WTP component at the individual level (ranging from 10 to $100 \%$ of total WTP to preserve the attributes over 100 years), which represents between 25 and $40 \%$ of total mean WTP estimates, at our sample level. This is a more conservative estimate than the ones usually found in the literature. However, the remaining $60-75 \%$ are interpreted as a mix of both use and non-use values for protecting the

\footnotetext{
${ }^{8}$ The fact that the mean WTP values or maximum WTP values for the ZCO area are really high (and can still seem unrealistic) is certainly due to a very low consideration of the cost attribute from the respondents living in this area. We highlight however that we are not interested in the absolute WTP values but rather in the ratio between the WTP during or beyond life expectancy and total WTP, and the

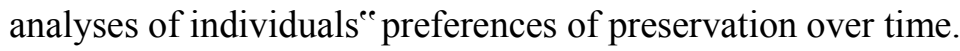


different attributes within the individualse lifetime, implying that total non-use values could potentially be much higher.

It is of course necessary to examine critically our approach through this case study implementation. As stated before, we are able through our method to securely capture exclusive non-use values for users through WTP for preservation beyond life expectancy, but the complementary WTP before life expectancy also certainly includes non-use components. This is the main limit of our definition of non-use values.

A possible interpretation could be to consider that non-use values held at a specific moment are perceived by the holder as being absolute and universal, and as such held continuously through time (even if the motivations underlying non-use values and their intensity are subject to changes over the individual's lifetime). In other words, most non-use values would usually appear "timeless" for the individual and would be perceived as independent of any considerations regarding their temporal existence, so that these values motivate both a WTP during and after life expectancy, in an equivalent way. That is, most non-use values that motivate a wish to preserve an ES today or in coming years would motivate in an equivalent way the wish that the ES will be preserved over a long time (after death). This would mean that the non-use value to preserve an ES beyond life expectancy is present in an equivalent proportion in the WTP to preserve it before life expectancy: to protect the ES until after one"s life expectancy, one would first have to pay for it to be preserved while still alive. In that case, at our sample scale, non-use values would also represent at least between $25-40 \%$ of the WTP during life expectancy, so that they would represent more than $50 \%$ of the total WTP. This comes closer to other estimates found in the literature.

More broadly, it could be argued that non-use values do not actually depend on an individual's life expectancy, but on perceptions associated with the different preservation durations 
considered, or on the motivations behind their commitment to preserve the coastal and marine ecosystems over time. During the surveys, most respondents associated 100 years with somewhat of an ideal ${ }^{9}$ that would guarantee the continued existence of these ecosystems and continued benefits to future generations. And when asked to rate different possible reasons behind their commitment to preserve coastal and marine ecosystems, all individuals gave a higher score to existence and bequest motivations, compared to use or option consideration. If 100 years is interpreted as pertaining to similar values by many individuals, it could be argued that age and life expectancy do not matter, and non-use values could in the end represent a more substantial part of WTP (since it can represent more than $90 \%$ for older individuals).

Age as a socio-economic variable was found to be significant in several of our models (tables A1 and A2 in appendix A), including when interacted with the non-monetary attributes under a continuous form for utility (table A3 in appendix A). These results imply that younger individuals have a higher utility associated with preservation options, and higher part-worth utilities for longer preservation periods concerning several attributes, principally those that are more focused on use values ${ }^{10}$. This would tend to confirm our hypothesis that age plays a role in WTP, and influences use and non-use values.

In this application, we chose to quantitatively describe preservation over time, but alternatives could have been used. It would for example be interesting to compare our results with a similar

\footnotetext{
${ }^{9}$ For some groups, 100 years preservation was perceived as something that must be guaranteed, from a deontological perspective. For others, it was more perceived as an utopist wish that would be great to fulfill but unrealistic since too far from the present.

${ }^{10}$ No interaction between age and non-monetary attributes are found to be significant for the ZCO area, although some are for the pooled model. For the VKP areas, interactions between age and the Quantity of animals fished or the Areas of Practice are highly significant and implies that younger people have higher part-worth utilities for these two attributes.
} 
choice experiment involving qualitative levels of time commitment for the attributes (such as "preservation during my life-time" and "preservation beyond my life-time", or from an intergenerational perspective as used in Scarborough and Bennett, 2008). In addition, shorter time horizons (e.g. 5 years) could also help differentiate further between use, option and non-use values for WTP during life expectancy.

A potential limitation of the approach we propose relates to the importance of discounting, since we are considering long time periods. Our study took place at a specific point in time, and our estimates are based on choices involving a simple monthly payment that individuals considered at this particular point in time, so that one could argue that no discounting is involved in the choices leading to the estimated values. If such discounting affects the choices, its effects concerning the preservation of attributes over longer time-periods are likely to be intrinsically taken into account via the log-linear specification of the utility function. One could argue that rather than relating strictly to time preference, the log-linear specification might also take into account the fact that the further distant in time the benefits considered, the greater the uncertainty. Respondents may in fact have considered this uncertainty when making their choices. Studying respondent ${ }^{\text {ee }}$ s perceptions in further detail with regards to the different timeframes used in this choice experiment could be an interesting topic for further research.

The approach presented in this paper provides a means of measuring an a minima non-use value for both users and non-users of an environmental asset. The approach is more robust than a subjective proportioning of value as in previous studies, and leads to suggest that the exclusive proportion of non-use value in total WTP may be lower than found in previous studies, although it is still substantial. By providing estimates of use and non-use values associated with the protection of several coral reef ecosystem services, this study also contributes to the literature on 
coral reef valuation where a need for more valuation work has recently been advocated (Laurans et al., 2013; Barbier, 2012; OGarra, 2009; Brander et al., 2007).

In addition, the survey results show that several contextual elements seem to have affected individuals ${ }^{e e}$ preferences and WTP. Analysis of the factors affecting attribute non-attendance, and especially cost attribute non-attendance, is the subject of further work currently underway. Substantial differences between both areas were observed, although these areas are very close geographically and share some characteristics in terms of environment and populations. In addition, different choices among similar types of population (age, income, tribe or non- tribe) were observed. Our models worked well in explaining and illustrating the different contextual elements of each area. The results confirm that during an economic valuation exercise, institutional, socio-economic and cultural contexts, as well as the status of the environment play a crucial role, which needs to be accounted for. This supports concerns that have been voiced regarding benefit transfer, which even within a small regional context need careful consideration before being implemented.

Overall, this work highlights both the difficulty of estimating NUV and the possibility, using the pragmatic approach we propose, to identify a lower bound for these values. We argue that the final estimates produced in this work are reliable enough to at least be used to raise awareness, or communicate about NUV, in the context New Caledonian coral reef ecosystems management. Our NUV estimates reflect the values that are held by users and non-users, and should be considered very seriously in decision-making. Ignoring these non-use values in management decision making for the coastal ecosystems considered would imply potentially significant loss of welfare.

In addition, the measurement of NUV in monetary terms may not be considered as sufficient in a decision-support context, in view of the multidimensionality of these values (Chan et al., 2012). 
Additional research is required on the extent to which stakeholders of decision-making processes are inclined to consider NUV estimates as well as other valuation metrics, in assessing the tradeoffs associated with the management of coastal development projects.

\section{Acknowledgements}

The work reported in this manuscript was supported by the French National Initiative for Coral Reefs (IFRECOR) program and the Australian Fisheries Research Development Corporation (FRDC project 2008/306). The authors are grateful to the IFRECOR, the members of the IFRECOR French national committee "TIT Economie" and the members of its local committee in New Caledonia. We are also grateful to the Ifremer Nouvelle-Calédonie for providing a working place, and ESCAL (Enquêtes statistiques Sondages Calédoniens) who helped us conducting the survey in New Caledonia. We thank all the individuals that participated in the focus group discussions and interviews when designing the survey and the choice experiments, and the New Caledonian populations for their participations in the surveys. We are also grateful to the Wealth from Ocean flagship for supporting this work.

The opinions expressed in this publication are those of the authors. They do not reflect the opinions of the Secretariat of the Pacific Community (SPC) or its members, and do not indicate a commitment from SPC to a course of action.

\section{Appendix A: MNL and Panel EC-RPL results with socio-economic variables}


Table A1 MNL and Panel EC-RPL models with non-continuous non monetary attributes and socio-economic variables

\begin{tabular}{|c|c|c|c|c|c|c|c|c|}
\hline & \multicolumn{3}{|c|}{ MNL } & \multicolumn{4}{|c|}{ EC-RPL } & \multirow{3}{*}{ Distribution } \\
\hline & \multirow{2}{*}{ Pooled } & \multirow{2}{*}{ VKP } & \multirow{2}{*}{$\mathrm{ZCO}$} & \multicolumn{2}{|c|}{ VKP } & \multicolumn{2}{|c|}{$\mathrm{zCO}$} & \\
\hline & & & & Mean & S.D & Mean & S.D & \\
\hline Payment & $-0.00017^{* * *}$ & $-0.00023 * * *$ & $-0.00011 *$ & $-0.00043 * * *$ & $0.00043 * * *$ & $-0.00017^{*}$ & $0.00017 *$ & $\mathrm{t}, 1$ \\
\hline Catches 20 years & 0.061 & 0.071 & 0.055 & $0.130^{*}$ & $0.339 * * *$ & 0.127 & $0.566^{* * *}$ & $\mathrm{n}$ \\
\hline Catches 50 years & $0.232 * * *$ & $0.264 * * *$ & $0.206^{* * *}$ & $0.326^{* * *}$ & $0.339 * * *$ & 0.322 & $0.566^{* * *}$ & $\mathrm{n}$ \\
\hline Catches 100 years & $0.233 * * *$ & $0.164 * *$ & $0.309 * * *$ & $0.283 * *$ & $0.339 * * *$ & 0.542 & $0.566^{* * *}$ & $\mathrm{n}$ \\
\hline Health 20 years & $0.102 * *$ & 0.058 & $0.152 * *$ & 0.098 & $0.523 * * *$ & 0.292 & $0.690 * * *$ & $\mathrm{n}$ \\
\hline Health 50 years & $0.324 * * *$ & $0.422 * * *$ & $0.224 * * *$ & $0.614 * * *$ & $0.523^{* * *}$ & 0.381 & $0.690 * * *$ & $\mathrm{n}$ \\
\hline Health 100 years & $0.385 * * *$ & $0.423 * * *$ & $0.358 * * *$ & $0.654 * * *$ & $0.523 * * *$ & 0.591 & $0.690 * * *$ & $\mathrm{n}$ \\
\hline Landscape 20 years & $0.117 * * *$ & $0.148^{* *}$ & $0.073^{*}$ & $0.193 * *$ & $0.353^{* * *}$ & 0.126 & $0.458 * * *$ & $\mathrm{n}$ \\
\hline Landscape 50 years & $0.162 * * *$ & $0.154 * * *$ & $0.180 * * *$ & $0.265 * * *$ & $0.353 * * *$ & 0.341 & $0.458 * * *$ & $\mathrm{n}$ \\
\hline Landscape 100 years & $0.268 * * *$ & $0.194 * * *$ & $0.365 * * *$ & $0.313 * * *$ & $0.353 * * *$ & 0.648 & $0.458 * * *$ & $\mathrm{n}$ \\
\hline Areas 20 years & -0.035 & 0.053 & $-0.137 * *$ & 0.067 & 0.255 & -0.318 & 0.298 & $\mathrm{n}$ \\
\hline Areas 50 years & $0.286^{* * *}$ & $0.347 * * *$ & $0.223 * * *$ & $0.478 * * *$ & $0.594 * * *$ & 0.364 & 0.385 & $\mathrm{n}$ \\
\hline Areas 100 years & $0.126^{* *}$ & -0.068 & $0.351^{* * *}$ & -0.089 & 0.055 & 0.680 & $0.678^{* * *}$ & $\mathrm{n}$ \\
\hline Age & $-0.019 * * *$ & $-0.038 * * *$ & -0.005 & -0.1 & $25^{*}$ & 0.0 & & \\
\hline Gender & -0.232 & -0.104 & $-0.402 * *$ & -0.0 & & -2.0 & & \\
\hline Income & $0.080 * * *$ & 0.057 & $0.110^{* * *}$ & 0.3 & & 0.1 & & \\
\hline Education level & $0.205^{* * *}$ & $0.227 * * *$ & $0.141^{*}$ & 0.38 & 21 & 1.0 & & \\
\hline Tribe & $0.633^{* * *}$ & $0.732 * * *$ & $0.461^{*}$ & 2.3 & & 3.0 & & \\
\hline ASCsq & 0.212 & -0.781 & $0.978 * *$ & -9.8 & & -1.3 & & \\
\hline Sigma Option 1,2 & & & & 1.5 & & 0.4 & & \\
\hline Sigma Status Quo & & & & 8.037 & $* * *$ & 8.491 & $* * *$ & \\
\hline Final Log-Likelihood & -2458.8 & -1265.4 & -1167.1 & -106 & 6.5 & -95 & & \\
\hline AIC & 1.556 & 1.487 & 1.629 & 1.2 & & 1.3 & & \\
\hline Pseudo- $\mathrm{R}^{2}$ & 0.131 & 0.141 & 0.129 & 0.4 & & 0.3 & & \\
\hline Halton Draws & & & & 35 & & 35 & & \\
\hline $\mathrm{N}$ & 398 & 216 & 182 & 21 & & 18 & & \\
\hline
\end{tabular}


Table A2 MNL and panel EC-RPL models results with log-linear utilities specifications and socio-economic variables

\begin{tabular}{|c|c|c|c|c|c|c|c|}
\hline & \multicolumn{2}{|c|}{ MNL } & \multicolumn{4}{|c|}{ EC-RPL } & \multirow{3}{*}{ Distribution } \\
\hline & \multirow{2}{*}{ VKP } & \multirow{2}{*}{ ZCO } & \multicolumn{2}{|c|}{ VKP } & \multicolumn{2}{|c|}{ ZCO } & \\
\hline & & & Mean & S.D. & Mean & S.D. & \\
\hline Payment & $-0.00026^{* * *}$ & $-0.00011^{*}$ & $-0.00040^{* * *}$ & $-0.00040^{* * *}$ & $-0.00015^{* *}$ & $-0.00015 * *$ & $\mathrm{t}, 1$ \\
\hline Ln Catches & $0.142 * * *$ & $0.1423^{* * *}$ & $0.163^{* * *}$ & $0.163 * * *$ & $0.164 * * *$ & $0.164 * * *$ & $\mathrm{t}, 1$ \\
\hline Ln Health & $0.239 * * *$ & $0.197 * * *$ & $0.307 * * *$ & $0.307 * * *$ & $0.246^{* * *}$ & $0.246^{* * *}$ & $\mathrm{t}, 1$ \\
\hline Ln Landscapes & $0.130 * * *$ & $0.168 * * *$ & $0.163^{* * *}$ & $0.163^{* * *}$ & $0.199^{* * *}$ & $0.199^{* * *}$ & $\mathrm{t}, 1$ \\
\hline Ln Areas (ZCO only) & & $0.136^{* * *}$ & & & $0.161^{* * *}$ & $0.161^{* * *}$ & $\mathrm{t}, 1$ \\
\hline Areas 20 years (VKP only) & 0.059 & & 0.056 & & & & fixed \\
\hline Areas 50 years (VKP only) & $0.338 * * *$ & & $0.425^{* * *}$ & $0.425^{* * *}$ & & & $\mathrm{t}, 1$ \\
\hline Areas 100 years (VKP only) & -0.042 & & -0.053 & & & & fixed \\
\hline Age & $-0.038 * * *$ & -0.0046 & -0 . & 109 & 0.0 & & \\
\hline Gender & -0.103 & $-0.398 * *$ & 0.2 & 50 & -0.2 & & \\
\hline Income & 0.057 & $0.108^{* * *}$ & 0.1 & 78 & 0.3 & & \\
\hline Education level & $0.228^{* *}$ & $0.142^{*}$ & 0.4 & 00 & 0.8 & $2 *$ & \\
\hline Tribe & $0.733 * * *$ & $0.461^{*}$ & 0.8 & 83 & 4.0 & & \\
\hline ASCsq & -0.832 & $0.959^{* *}$ & -9.9 & $28^{*}$ & -1. & & \\
\hline Sigma Option 1,2 & & & 5.43 & $1 * * *$ & 5.45 & $2 * * *$ & \\
\hline Sigma Status Quo & & & 3.66 & $9^{* *}$ & 2.9 & 10 & \\
\hline Final Log-Likelihood & -1270.6 & -1172.1 & -10 & 30.6 & -97 & 8.1 & \\
\hline AIC & 1.486 & 1.625 & 1.2 & & 1.3 & 61 & \\
\hline Adjusted Pseudo-R ${ }^{2}$ & 0.139 & 0.128 & 0.4 & & 0.3 & 86 & \\
\hline Halton Draws & & & 3 & 0 & 35 & 50 & \\
\hline $\mathrm{N}$ & 216 & 182 & 2 & 6 & 18 & 32 & \\
\hline
\end{tabular}

*** Significant at the $1 \%$ level** Significant at the 5\% level * Significant at the $10 \%$ level 
Table A3 MNL and Panel EC-RPL with log-linear utility specifications and Age interacting with non-monetary attributes

\begin{tabular}{|c|c|c|c|c|c|c|c|c|}
\hline & \multicolumn{3}{|c|}{ MNL } & \multicolumn{4}{|c|}{ EC-RPL } & \multirow{3}{*}{ Distribution } \\
\hline & \multirow{2}{*}{ Pooled } & \multirow{2}{*}{ VKP } & \multirow{2}{*}{$\mathrm{ZCO}$} & \multicolumn{2}{|c|}{ VKP } & \multicolumn{2}{|c|}{$\mathrm{ZCO}$} & \\
\hline & & & & Mean & S.D & Mean & S.D & \\
\hline Payment & $-0.00014 * * *$ & $-0.00018 * * *$ & $-0.00010^{*}$ & $-0.00031 * * *$ & $-0.00031 * * *$ & $-0.00016^{* *}$ & $-0.00016^{* *}$ & $\mathrm{t}, 1$ \\
\hline Ln Catches & $0.156^{* * *}$ & $0.184 * * *$ & $0.126^{* * *}$ & $0.190 * * *$ & $0.190 * * *$ & $0.142 * * *$ & $0.142 * * *$ & $\mathrm{t}, 1$ \\
\hline Ln Health & $0.221 * * *$ & $0.235^{* * *}$ & $0.199 * * *$ & $0.324 * * *$ & $0.324 * * *$ & $0.265^{* * *}$ & $0.265^{* * *}$ & $\mathrm{t}, 1$ \\
\hline Ln Landscapes & $0.164 * * *$ & $0.168^{* * *}$ & $0.164 * * *$ & $0.201 * * *$ & $0.201 * * *$ & $0.183^{* * *}$ & $0.183^{* * *}$ & $\mathrm{t}, 1$ \\
\hline Ln Areas & $0.124 * * *$ & $0.134 * * *$ & $0.118^{* * *}$ & $0.141^{* * *}$ & $0.141^{* * *}$ & $0.109^{* * *}$ & $0.109 * * *$ & $\mathrm{t}, 1$ \\
\hline Catches * Age & -0.00003 & $-0.00008^{* * *}$ & 0.00001 & -0.0 & 0005 & 0.00 & 003 & \\
\hline Health * Age & -0.00002 & -0.000005 & -0.00003 & -0.0 & 0003 & -0.0 & 005 & \\
\hline Landscapes * Age & $-0.00004^{*}$ & $-0.00008^{* *}$ & 0.000008 & -0.00 & $007 *$ & 0.00 & 003 & \\
\hline Areas * Age & $-0.00004 *$ & $-0.0001 * * *$ & $0.00001^{*}$ & -0.00 & $08 * *$ & 0.00 & $007 *$ & \\
\hline ASCsq & $0.296^{* * *}$ & 0.032 & $0.581 * * *$ & -9.55 & $3^{* * *}$ & -4.42 & $4^{* * *}$ & \\
\hline Sigma Option 1,2 & & & & 8.57 & $7 * * *$ & 3.75 & $8 * * *$ & \\
\hline Sigma Status Quo & & & & $2 .($ & 19 & 2.9 & $0 * *$ & \\
\hline Final Log-Likelihood & -2960.4 & -1513.8 & -1425.4 & -12 & 38.1 & -11 & 65.4 & \\
\hline AIC & 1.625 & 1.561 & 1.685 & 1.2 & 81 & 1.3 & 82 & \\
\hline Pseudo- $\mathrm{R}^{2}$ & 0.105 & 0.110 & 0.105 & 0. & & 0.3 & 75 & \\
\hline Halton Draws & & & & 3 & & 3 & 50 & \\
\hline $\mathrm{N}$ & 457 & 244 & 213 & 2 & 14 & 2 & 3 & \\
\hline
\end{tabular}

*** Significant at the $1 \%$ level** Significant at the $5 \%$ level $*$ Significant at the $10 \%$ level 


\section{References}

1 Adamowicz, W., P. Boxall, M. Williams and J. Louviere. 1998. „Stated Preference Approaches to

2 Measuring Passive Use Values: Choice Experiments Versus Contingent Valuation“e, American 3 Journal of Agricultural Economics.

4 Adamowicz, W. 2004. „What"s it worth? An examination of historical trends and future directions 5

7 Aldred, J. 1994. Existence value, welfare and altruism. Environ. Values 3.4, 381-402.

8 Attfield, R. 1998. Existence value and intrinsic value. Ecological Economics 24: 163-168.

9 Barkmann, J., K. Glenk, A. Keil, C. Leemhuis, et al. 2008. Confronting unfamiliarity with

Barbier, E. B. 2012. Progress and Challenges in Valuing Coastal and Marine Ecosystem Services. Review Environmental Economics and Policy 6(1): 1-19.

Bateman, I. J., R.T. Carson, B. Day., W. Hanemann, et al. 2002. Economic Valuation with Stated Preference Techniques: A Manual, Edward Elgar, Cheltenham, UK.

Bateman, I., 2008. The existence (and measurement) of existence values reconsidered. In: Grant, F., Young, J., Harrison, P., Sykes, M., Skourtos, M., Rounsevell, M., Kluvánková- Oravská, T., Settele, J., Musche, M., Anton, C., Watt, A. (Eds.), Ecosystem Services and Drivers of Biodiversity Change. Report of the RUBICODE e-conference.

Beharry-Borg, N., R. Scarpa. 2010. Valuing quality changes in Caribbean coastal waters for heterogeneous beach visitors. Ecological Economics 69:1124-1139. 
Blamey, R. K. , J. W. Bennett and M. D. Morrison. 1999. Yea-Saying in Contingent Valuation Surveys. Land Economics 75(1): 126-141.

Brander, L. M., P. Van Beukering, H. S.J. Cesar. 2007. The recreational value of coral reefs: A meta-analysis. Ecological Economics 62: 209-218.

Brookshire, D., L. Eubanks and A. Randall. 1983. Estimating option prices and existence values for Wildlife Resources. Land Economics 59: 1-15.

Boyd, J., S. Banzhaf. 2007. What are ecosystem services? The need for standardized environmental accounting units. Ecological Economics 63(2-3): 616-626.

Campbell, D., W.G. Hutchinson, R. Scarpa. 2008. Incorporating Discontinuous Preferences into the Analysis of Discrete Choice Experiments. Environmental and Resource Economics 41(3): $401-417$.

Carson, R.T., M. Hanemann, R.J. Kopp, et al. 1992. A Contingent Valuation Study of Lost Passive use Values Resulting from the Exxon Valdez Oil Spill. Attorney General of the State of Alaska. Anchorage.

Carson, R.T., N.E. Flores and R.C. Mitchell. 1999. „The Theory and Measurement of Passive Use Value , in Bateman, I.J and Willis, K.G. (eds.), Valuing Environmental Preferences: Theory and Practice of the Contingent Valuation Method in the US, EC, and Developing Countries. Oxford: Oxford University Press.

Chan, K.M.A., T. Satterfield, J. Goldstein. 2012. Rethinking ecosystem services to better address and navigate cultural values. Ecological Economics 74: 8-18.

Chilton, S.M., W.G. Hutchinson. 2000. A note on the warm glow of giving and scope sensitivity in contingent valuation studies. Journal of Economic Psychology 21: 343-349.

Chrzan, K., B. Orme. 2000. An Overview and Comparison of Design Strategies for Choice-Based Conjoint Analysis, Sawtooth Software research paper series. 
Costanza, R., R. d"Arge, R. deGroot, et al. 1997. The value of the world's ecosystem services and natural capital. Nature 387: 253-260.

Cummings, RG, G.W. Harrison. 1995. The measurement and decomposition of non use values: a critical review. Environ Resour Econ 5:225-247.

Daniel, TC, A. Muhar, A. Arnberger, O. Aznarc et al. 2012. Contributions of cultural services to the ecosystem services agenda. Proc Natl Acad Sci USA 109:8812-8819.

Hanley, N., R. Wright, V. Adamowicz. 1998. Using choice experiments to value the environment. Environmental and Resource Economics 11: 413-428.

Hanley, N., F. Schläpfer, J. Spurgeon. 2000. Aggregating the benefits of environmental improvements: distance-decay functions for use and non-use values. Journal of Environmental Management 68 (3): 297-304

Hensher, D.A., J.M. Rose, and W.H. Greene. 2005. Applied choice analysis: A primer. Cambridge: Cambridge University Press.

Hess, S, D.A. Hensher. 2010. Using conditioning on observed choices to retrieve individualspecific attribute processing strategies. Transp Res B 44(6):781-790.

Hoyos, D. 2010. The state of the art of environmental valuation with discrete choice experiments. Ecological economics 69: 1595-1603.

Hussen Alemu, M., M. R. Mørkbak, S. B. Olsen, C. L. Jensen. 2012. Attending to the Reasons for Attribute Non-attendance in Choice Experiments. Environ Resource Econ. 54 (3): 333-359.

Kahneman, D., Knetsch, J.L. 1992. Valuing public goods: The purchase of moral satisfaction. Journal of Environmental Economics and Management 22: 57-70.

Kaoru, Y., 1993. Differentiating use and nonuse values for coastal pond water quality improvements. Environ Resource Econ. 3 (55): 487-494. 
Kontogianni, A., C. Tourkolias, A. Machleras, M. Skourtos. 2012. Service providing units, existence values and the valuation of endangered species: A methodological test. Ecological Economics 79: 97-104.

Krutilla, J.V. 1967. Conservation reconsidered. The American Economic Review 57: 777-789.

Krutilla, J. V., and A. C. Fisher. 1985. The economics of natural environments: Studies in the valuation of commodity and amenity resources. Washington, DC: Resources for the Future.

Laurans, Y., N. Pascal., T. Binet, et al. 2013a. Economic valuation of ecosystem services from coral reefs in the South Pacific: taking stock of recent experience. Journal of Environmental Management 116: 135-144.

Liu, S., R. Costanza, S. Farber, A. Troy. 2010, Valuing ecosystem services Theory, practice, and the need for a transdisciplinary synthesis, Ann. N.Y. Acad. Sci. 1185 54-78.

Loomis, J. 1988. Broadening the Concept and Measurement of Existence Value. Northeastern Journal of Agricultural and Resource Economics. 23-29.

Mazzotta, M.J., J. Kline. 1995. Environmental Philosophy and the concept of non-use values. Land Economics, 71(2) :244-49.

McFadden, D. 1974. Conditional logit analysis of qualitative choice behavior. In P. Zarembka (ed.) Frontiers in Econometrics. New York: Academic Press, 105-142.

McVittie, A., D. Moran. 2010. Valuing the non-use benefits of marine conservation zones: An application to the UK Marine Bill. Ecological Economics 70: 413-424.

Millennium Ecosystem Assessment. 2005. Ecosystems and Human Well-being: Current States and Trends. Island Press.Washington, DC.

O'Garra, T. 2009. Bequest values for marine resources: How important for indigenous communities in less- developed economies? Environmental and Resource Economics 44, 179-202. 
Ojea, E., M. L. Loureiro. 2007. Altruistic, egoistic and biospheric values in willingness to pay (WTP) for wildlife. Ecological Economics 63: 807-814.

Pearce, D. and D. Moran. 1994. The Economic Value of Biodiversity. Earthscan Publications, London, U.K.

Sattout, E.J., S.N. Talhouk, P.D.S. Caligari. 2007. Economic value of cedar relics in Lebanon: an application of contingent valuation method for conservation. Ecological Economics 61: 315322.

Scarborough, H., J. Bennett. 2008. Estimating intergenerational distribution preferences, Ecological Economics, 66(4): 575-583.

Scarpa, R., T.J. Gilbride, D. Campbell and D.A. Hensher. 2009. Modelling attribute non-attendance in choice experiments for rural landscape valuation. European Review of Agricultural Economics, 36(2): 151-174.

Schumann, P. 2011. The Valuation of Marine Ecosystem Goods and Services in the Caribbean. Wilmington, NC: University of North Carolina Wilmington.

Silberman, J., D.A. Gerlowsky, N.A. Williams. 1992. Estimating Existence Value for users and non-users of New Jersey Beaches. Land Economics 68(2): 225-36.

Spurgeon, J. 2004. Valuation of Coral Reefs: The Next Ten Years. In Economic Valuation and Policy Priorities for Sustainable Management of Coral Reefs, ed. M Ahmed, CK Chong and H Cesar, World Fish Centre, Penang.

Stevens, T.H. et al. 1991. Measuring the existence value of wildlife: what do CVM estimates really show? Land Economics 67: 390-400.

Sukhdev, P. 2008. The Economics of Ecosystems and Biodiversity (TEEB): An Interim Report . European Communities. A Banson Production. Cambridge, UK. 
115 Swait, J. 1994. A structural equation model of latent segmentation and product choice for cross116 sectional revealed preference data. Journal of Retailing and Consumer Service 1: 77-89.

117 Thurstone, L. L. 1927. A law of comparative judgment. Psychological Review 34: 273-286.

118 Train, K. 2003. Discrete Choice Models with Simulation. Cambridge University Press, Cambridge. 119 Togridou, A., T. Howardas, JD. Pantis. 2006. Determinants of visitors ${ }^{e e}$ willingness to pay for the 120 National Marine Park of Zakynthos, Greece. Ecol Econ 60(1): 308-319.

121 Turner, R. K., J. Paavola, P. Cooper, et al. 2003. Valuing nature: lessons learned and future 122 research directions. Ecological Economics 46: 493-510

123 Walsh, R.G., J.B. Loomis, R.A. Gillman. 1984. Valuing option, existence and bequest demands for 124 wilderness. Land Econ 60(1):14-29.

125 Wattage, P., S. Mardle. 2008. Total economic value of wetland conservation in Sri Lanka 126 identifying use and non-use values. Wetlands Ecology and Management 16: 359-369.

127 Windle, J., J. Rolfe. 2005. Assessing Non-use Values for Environmental Protection of an Estuary in 128 a Great Barrier Reef Catchment. Australasian Journal of Environmental Management, 12(3): 147-155. 